\title{
Synthesis and Biological Evaluation of Novel 6-(3-(4, 5-Dihydro-1,5-diphenyl-1H-pyrazol-3-yl)phenylamino) Pyridazin-3(2H)-one Derivatives
}

\author{
Shrikrishna D. Tupare ${ }^{1}$, Satish A. Dake ${ }^{1}$, Santosh V. Nalage², Sidhanath V. Bhosale ${ }^{2}$, \\ Rajita D. Ingle ${ }^{1}$, Rajendra P. Pawar ${ }^{1 *}$ \\ ${ }^{1}$ Department of Chemistry, Deogiri College, Aurangabad, India \\ ${ }^{2}$ Polymers and Functional Materials Division, CSIR-Indian Institute of Chemical Technology, Hyderabad, India \\ Email: *rppawar@yahoo.com
}

Received September 12, 2012; revised October 24, 2012; accepted November 4, 2012

\begin{abstract}
Pyrazoles are important nitrogen containing 5-membered heterocyclic compounds. Numerous pyrazoline derivatives have been found to possess considerable biological activities, which stimulated the research activity in this field. Several 1,3,5-Triphenyl-1H-pyrazole containing 6-aminopyridazin-3(2H)-one derivatives has been synthesized. These new compounds were characterized using IR, ${ }^{1} \mathrm{H}-\mathrm{NMR}$ and Mass spectra and Elemental analysis. They possess some potent biological activities. Therefore biological screening of novel compounds has been also done.
\end{abstract}

Keywords: Antibacterial Activity; Antifungal Activity; Efficient Synthesis

\section{Introduction}

Nitrogen heterocycles are of synthetic interest because they constitute an important class of natural and synthetic products, many of which exhibited useful biological activities [1]. An interest in five member systems with two adjacent nitrogen atoms occurs from saturated and partially saturated pyrazoles in biologically active compounds and natural products $[2,3]$.

Substituted pyrazolines and their derivatives embedded with variety of functional groups are important biological agents. Thus, a significant amount of research activity has been directed towards this class. In particular, they are used as antitumor, antibacterial, antifungal, antiviral, antiparasitic, anti-tubercular and insecticidal agents. In recent years, a significant portion of research in heterocyclic chemistry has been devoted to 2-pyrazolines containing different aryl groups as substituents, as evident in literature. Pyrazolines have been reported to show a broad spectrum of biological activities including antibacterial [4], antifungal [5], anti-inflammatory [6], and antidepressant actevities [7]. The pyrazoline function is quite stable, and has inspired chemists to utilize this stable fragment in bioactive moieties to synthesize new compounds possessing biological activities.

Several methods are employed in the synthesis of pyrazolines, including the condensation of chalcones with

*Corresponding author. hydrazine, phenyl hydrazine [8-12], and condensation of chalcones with thiosemicarbazide in ethanol under strong basic or acidic conditions [13]. The desired chalcones [14] were synthesized by reacting 6-(3-acetyl-phenylamino) pyridazin-3(2H)-one with substituted aromatic aldehydes in presence of alkali. In a typical case, equimolar quantities of chalcones and phenyl hydrazine hydrochloride in presence of acetic acid and few crystals of sodium acetate, led the formation of pyrazolines 3a-I (Scheme 1); continuing our investigations on the application of above mentioned an efficient and practical procedure for the synthesis of 1,3,5-Triaryl-2-pyrimidines with chalcones and phenylhydrazine hydrochloride in sodium acetateacetic acid aqueous solution has been reported.

\section{Results and Discussion}

A variety of methods were reported for the preparation of this class of compounds. After pioneering work of Fischer and Knoevenagel in $19^{\text {th }}$ century, the reaction of $\alpha, \beta$ unsaturated aldehydes and ketones with phenylhydrazine in acetic acid under reflux condition became the most popular method of the preparation of pyrazolines [14]. In 1998, Powers et al. [15] reported the reaction of chalcones and phenylhydrazine hydrochloride in the presence of sodium hydroxide which was carried out in absolute ethanol at $70^{\circ} \mathrm{C}$, but; there are disadvantages such as longer the reaction time $(8 \mathrm{~h})$ etc. In 2005 , the synthesis of 3,5-diaryl-2-pyra-zolines by the reaction of chloro 
chalcones with phenylhydrazine in acetic acid under reflux condition was reported for three hours. Effect of the reaction conditions on chalcones and phenyl hydrazine hydrochloride was summarized in Table 1. When the molar ratio of chalcones $\mathbf{3}$ and phenyl hydrazine hydrochloride was 1:1, the yield of 1,3,5-triphenyl pyrazoline obtained was very less. But by increasing the molar ratio to $1: 2$ and 1:3 the yield of products were also increased. It may be that sodium acetate is in favour the release of phenylhydrazine from phenylhy-drazine hydrochloride [14]. So reaction condition we chose were the molar ratio of chalcone:phenylhydrazine: sodium acetate was 1:3:0.15. We have performed the reaction of chalcone with phenylhydrazine hydrochloride by refluxing at $110^{\circ} \mathrm{C}$ the yield of pyrazoline was $48 \%$ - $71 \%$ (Table 1).

From the results, the optimum reaction condition was chosen: Chalcone ( $3 \mathrm{mmol})$, phenylhydrazine hydrochloride $(6 \mathrm{mmol})$, Sodium acetate $(0.3 \mathrm{mmol})$.

Under this reaction system, a series of experiments for synthesis of pyridazin-3(2H)-one derivative were performed.

The following sequence of reaction appears to afford a satisfactory explanation of the mode of formation of the products (Scheme 2). This reaction involves the initial formation of an arylhydrazone with subsequent attack of nitrogen upon the carbon-carbon double bond.

\section{Antibacterial and Antifungal Activity}

All of the novel synthesized compounds were screened for their antifungal and antibacterial activity against the Gram - ve bacteria Escherichia coli (ATCC 8739) and Gram + ve bacteria Staphylococcus aureus (ATCC 6538), in addition to their antifungal activity against Aspergillus niger (ATCC 16404) Candida albicans (ATCC 10231) using ager diffusion method $[16,17]$ at a concentration 20 $\mathrm{mg} / \mathrm{mL}$. DMSO used as a solvent. Compound 3f shows highly efficient antibacterial activity against $S$. aureus (ATCC 6538) more than Penicillin standard. Compound 3b show was also found to be efficient equivalent to standard penicillin.

Standard Grysofulvin showed antifungal against $A$. Niger (ATCC 16404) zone of inhibition is $24 \mathrm{~mm}$ and $B$. albicans (ATCC 10231) shows zone of inhibition is 23 $\mathrm{mm}$, where as compounds $\mathbf{3 e} \& \mathbf{3 b}$ are found to be highly potent against $A$. niger (ATCC 16404) and compound 3f are highly efficient against $B$. albicans (ATCC 10231). From the result it can be conclude that compound $4 \mathrm{f}$ has antibacterial and antifungal activity more efficient than the standards used in this research work. The results, recorded as average diameter of inhibition zone in $\mathrm{mm}$, are given in Table 2.

\section{Experimental}

General Procedures: Melting points were determined in open capillary tubes and are uncorrected. The purities of the compounds were checked on silica-gel-coated $\mathrm{Al}$ plates. IR spectra were recorded in $\mathrm{KBr}$ on a Perkin Elmer Spectrum BX series FT-IR spectrometer. ${ }^{1} \mathrm{HNMR}$ spectra were recorded on Bruker DRX $300 \mathrm{MHz}$ NMR spectrometer using TMS as internal standard and mass spectra on a Jeol D-300 spectrometer.

We synthesized novel chalcones using conventional method in the literature and used in this research work.

Pyridazin-3(2H)-one(3a-3l): Chalcone(6-(3-((E)-4phenylbut-3-enoyl)phenylamino)pyridazzin-3(2H)one (1 mmol), phenyl hydrazine hydrochloride $(2 \mathrm{mmol})$, sodium acetate $(0.3 \mathrm{mmol})$ in $2-3$ drops of acetic acid was reflux for $3-4 \mathrm{hrs}$ at $110^{\circ} \mathrm{C}$ temp. The solid was collected and recrystalized from alcohol to give corresponding 2-pyrazolines (Scheme 1).<smiles>[R][X]1ccccc1C1CC(c2cccc(Nc3ccc(=O)[nH]n3)c2)=NN1c1ccccc1</smiles>

Scheme 1. Formation of pyrazolines (3a-l).

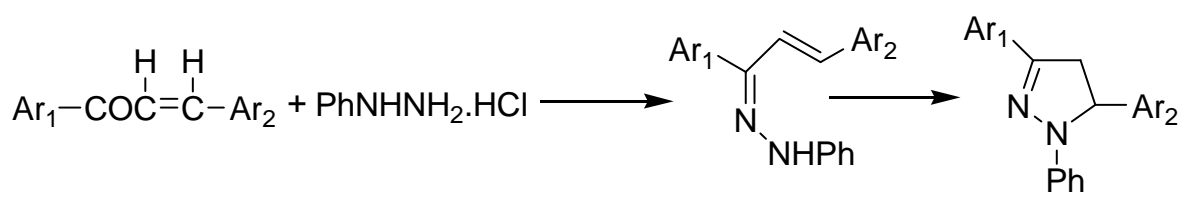

Scheme 2. The possible mechanism for the formation of products. 
Table 1. Synthesis of pyridazin-3(2H)-one derivatives in sodium acetate and acetic acid.

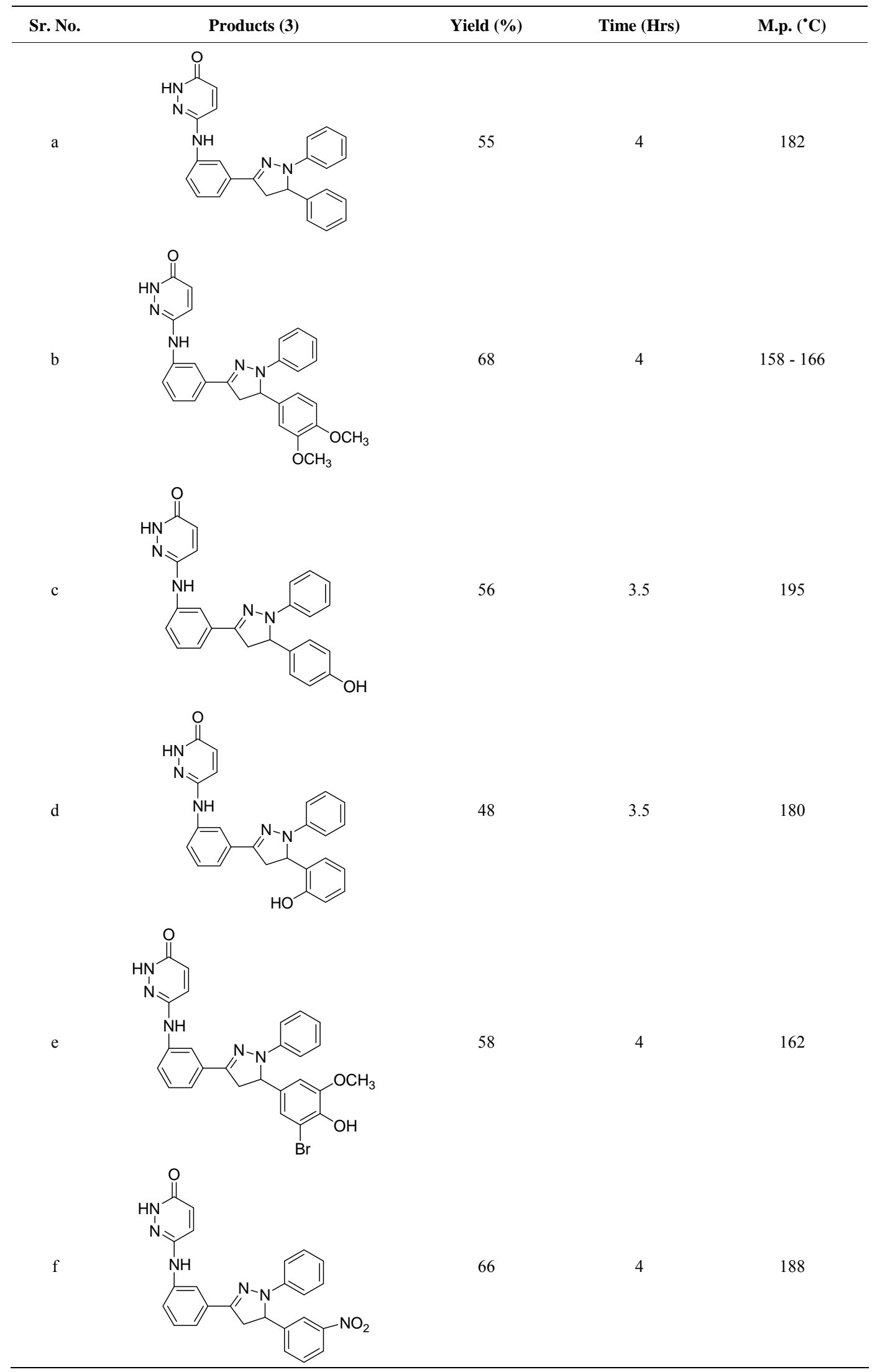




\section{Continued}

g<smiles>CNc1ccc(=O)[nH]n1</smiles>

h<smiles>O=c1ccc(Nc2cccc(C3=NN(c4ccccc4)C(c4ccc([N+](=O)[O-])cc4)C3)c2)n[nH]1</smiles>

i

j<smiles>COc1ccc(C2CC(c3cccc(Nc4ccc(=O)[nH]n4)c3)=NN2c2ccccc2)cc1</smiles>

$\mathrm{k}$<smiles>O=c1ccc(Nc2cccc(C3=NN(c4ccccc4)C(c4ccccc4[N+](=O)[O-])C3)c2)n[nH]1</smiles>

68

71

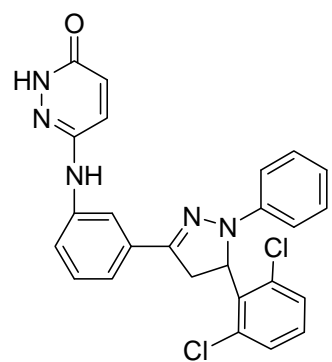

70

48<smiles>COc1cc(C2CC(c3cccc(Nc4ccc(=O)[nH]n4)c3)=NN2c2ccccc2)cc(OC)c1OC</smiles>

$\mathrm{OCH}_{3}$
4

$190-193$

3.5

181

3.5

161

$185-190$

4

4

203

政 
Table 2. Antifungal and antibacterial screening results of the synthesized 1,3,5-triaryl-2-pyrazolines derivatives.

\begin{tabular}{|c|c|c|c|c|}
\hline \multirow{2}{*}{ Comp. Codes } & \multicolumn{2}{|c|}{ Antibacterial Activity } & \multicolumn{2}{|c|}{ Antifungal Activity } \\
\hline & E. coli (ATCC 8739) & S. aureus (ATCC 6538) & A. niger (АTCC 16404) & B. albicans (ATCC 10231) \\
\hline $3 a$ & 15 & 15 & 13. & 22.5 \\
\hline $3 b$ & 17 & 20 & 25.5 & 13 \\
\hline $3 \mathrm{c}$ & 19 & 16 & 20.5 & 18 \\
\hline $3 d$ & 16 & 15 & 13.5 & 16 \\
\hline $3 \mathrm{e}$ & 19 & 12 & 29.5 & 16.5 \\
\hline $3 f$ & 12 & 21 & - & 24.5 \\
\hline $3 g$ & 15 & 19 & - & 18 \\
\hline $3 \mathrm{~h}$ & 15 & 15 & 16.5 & 17 \\
\hline $3 \mathrm{i}$ & 13 & 13 & 14.5 & 17.5 \\
\hline $3 \mathrm{j}$ & 16 & 11 & - & 13 \\
\hline $3 \mathrm{k}$ & 14 & 13 & - & 15.5 \\
\hline 31 & 16 & 11 & 13.5 & 15.5 \\
\hline Penicillin & 22 & 20 & - & - \\
\hline Grysofulvin & - & - & 24 & 23 \\
\hline
\end{tabular}

${ }^{*}$ Zone of inhibition in $\mathrm{mm}$.

\section{Spectral Analysis}

Compound (3a): Yield 55\%, M. P. $182^{\circ} \mathrm{C}$; IR (KBr): 3240 (Ar-C=C Str.), 3250 (N-H Str.), $1675(\mathrm{C}=\mathrm{O})$;

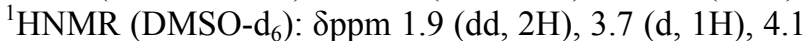
(brs, 1H, -NH), 5.9 (dd, 1H), 6.4 (dd, 1H, Ar-H), 6.7 (dd, 1H), 6.8 (dd, 1H, Ar-H), 6.9 (s, 1H, Ar-H), 7.1 (brs, 1H, -NH), 6.40 - 7.05 (s, 5H, Ar-H), 7.1 (t, 1H, Ar-H), 7.05 7.25 (s, 5H, Ar-H); Mass; (m/z), 407; Elemental analysis (\% for) $\mathrm{C}_{25} \mathrm{H}_{21} \mathrm{~N}_{5} \mathrm{O}$, Calcd. C, 73.69; H, 5.19; N, 17.19; O, 03.95; found. C, 74.20; H, 5.24; N, 17.44; O, 4.00 .

Compound (3b): ${ }^{1}$ HNMR (DMSO- $\mathrm{d}_{6}$ ): $\delta$ ppm 1.8 (dd, $2 \mathrm{H}), 3.5(\mathrm{~d}, 1 \mathrm{H}), 3.8\left(\mathrm{~s}, 6 \mathrm{H},-\mathrm{OCH}_{3}\right), 4.1$ (brs, $\left.1 \mathrm{H},-\mathrm{NH}\right)$, $5.9(\mathrm{dd}, 1 \mathrm{H}), 6.4(\mathrm{dd}, 1 \mathrm{H}, \mathrm{Ar}-\mathrm{H}), 6.45(\mathrm{dd}, 1 \mathrm{H}, \mathrm{Ar}-\mathrm{H})$, 6.50 (s, 1H, Ar-H), 6.60 (dd, 1H, Ar-H), 6.7 (dd, 1H), 6.8 (dd, 1H, Ar-H), 6.9 (s, 1H, Ar-H), $6.41-7.07$ (s, 5H, Ar-H), 7.1 (brs, 1H, -NH), 7.1 (t, 1H, Ar-H). Mass; (m/z), 465; Elemental analysis (\% for) $\mathrm{C}_{27} \mathrm{H}_{25} \mathrm{~N}_{5} \mathrm{O}_{3}$ Calcd. C, 69.36; H, 5.39; N, 14.98; O, 10.27; found. C, 70.16; H, 5.42; N, 14.98; O, 10.30 .

Compound (3d): Yield $48 \%$, M. P. $180^{\circ} \mathrm{C}$; IR (KBr): 3268 (Ar-C=C Str.), 3220 (N-H Str.), $1677(\mathrm{C}=\mathrm{O}) ; 3260$ (-OH); ${ }^{1}$ HNMR (DMSO-d $\mathrm{d}_{6}$ ): $\delta$ ppm 1.7 (dd, $\left.2 \mathrm{H}\right), 3.7$ (d, 1H), 4.1 (brs, 1H, -NH), 5.1 (brs, $1 \mathrm{H},-\mathrm{OH}), 5.9$ (dd, $1 \mathrm{H}), 6.4(\mathrm{dd}, 1 \mathrm{H}, \mathrm{Ar}-\mathrm{H}), 6.7(\mathrm{dd}, 1 \mathrm{H}), 6.8(\mathrm{dd}, 1 \mathrm{H}, \mathrm{Ar}-\mathrm{H})$, 6.9 (s, $1 \mathrm{H}, \mathrm{Ar}-\mathrm{H}), 6.41-7.02$ (s, 5H, Ar-H), 7.1 (brs, $1 \mathrm{H}$, -NH), 6.45 (dd, 1H, Ar-H), 6.65 (t, 1H, Ar-H), 6.69 (dd, 1H, Ar-H), 6.90 (t, 1H, Ar-H), 7.1 (t, 1H, Ar-H). Mass; $(\mathrm{m} / \mathrm{z}), 465$; Elemental analysis (\% for) $\mathrm{C}_{25} \mathrm{H}_{21} \mathrm{~N}_{5} \mathrm{O}_{2}$ Calcd. C, 70.91; H, 5.00; N, 16.54; O, 7.56; found. C, 80.06; H, $5.00 ; \mathrm{N}, 16.78 ; \mathrm{O}, 7.70$.

Compound (3f): Yield $66 \%$, M. P. $188^{\circ} \mathrm{C}$; IR (KBr): 3253 (Ar-C=C Str.), 3230 (N-H Str.), $1677(\mathrm{C}=\mathrm{O}), 1368$ $\left(\mathrm{NO}_{2}\right) ;{ }^{1} \mathrm{HNMR}\left(\mathrm{DMSO}-\mathrm{d}_{6}\right): \delta$ ppm $1.7(\mathrm{dd}, 2 \mathrm{H}), 3.7(\mathrm{~d}$, 1H), 4.1 (brs, 1H, -NH), 5.9 (dd, 1H), 6.4 (dd, 1H, Ar-H), $6.7(\mathrm{dd}, 1 \mathrm{H}), 6.8(\mathrm{dd}, 1 \mathrm{H}, \mathrm{Ar}-\mathrm{H}), 6.9(\mathrm{~s}, 1 \mathrm{H}, \mathrm{Ar}-\mathrm{H}), 7.1$ (brs, 1H, -NH), $7.1(\mathrm{t}, 1 \mathrm{H}, \mathrm{Ar}-\mathrm{H}), 6.40-7.05(\mathrm{~s}, 5 \mathrm{H}$, Ar-H), 7.45 (t, 1H, Ar-H), 7.50 (dd, 1H, Ar-H), 8.05 (dd, $2 \mathrm{H}$, Ar-H), Mass; (m/z), 452; Elemental analysis (\% for) $\mathrm{C}_{25} \mathrm{H}_{20} \mathrm{~N}_{6} \mathrm{O}_{3}$ Calcd. C, 66.36; H, 4.46; N, 18.54; O, 10.61; found. C, 67.06; H, 4.57; N, 18.57; O, 10.70 .

Compound (3l): Yield $48 \%$, M.P. $180^{\circ} \mathrm{C}$; IR (KBr): 3268 (Ar-C=C Str.), 3220 (N-H Str.), 1677 (C=O), 762 (-Cl); ${ }^{1} \mathrm{HNMR}$ (DMSO-d ${ }_{6}$ ): $\delta$ ppm 1.9 (dd, 2H), 3.6 (d, 1H), 4.2 (brs, 1H, -NH), 5.9 (dd, 1H), 6.4 (dd, 1H, Ar-H), 6.7 (dd, 1H), 6.8 (dd, 1H, Ar-H), 6.9 (s, 1H, Ar-H), 6.95 (t, 1H, Ar-H), 7.1 (brs, 1H, -NH), 7.1 (t, 1H, Ar-H), 6.41 - 7.06 (s, 5H, Ar-H), 7.15 (dd, 2H, Ar-H). Mass; (m/z), 475; Elemental analysis (\% for) $\mathrm{C}_{25} \mathrm{H}_{19} \mathrm{Cl}_{2} \mathrm{~N}_{5} \mathrm{O}$ Calcd. C, 63.03; H, 4.02; Cl, 14.49; N, 14.74; O, 3.36; found. C, $62.93 ; \mathrm{H}, 4.12 ; \mathrm{Cl}, 14.50 ; \mathrm{N}, 14.78 ; \mathrm{O}, 3.40$.

\section{Conclusion}

This methodology is maintaining environmental friendly approach for the synthesis of pyridazin-3(2H)-one de- 
rivatives using sodium acetate and acetic acid. But by increasing the molar ratio to $1: 2$ and $1: 3$ the yields of increased, it may be that sodium acetate is in favour of release of phenylhydrazine from phenylhydrazine hydrochloride. So reaction condition we chose were the molar ratio of chalcone:phenylhydrazine:sodium acetate was 1.0:3.0:0.15. We have performed the reaction of chalcones with phenylhydrazine hydrochloride by refluxing at $110^{\circ} \mathrm{C}$, the moderate to good $\%$ yield of pyrazoline derivatives is observed. The synthesized compounds were further subjected for biological screening. Some pyrazoline derivatives are found to be more potent.

\section{Acknowledgements}

The authors are thankful to the Principal Dr. Shivaji N. Thore, Deogiri College, Aurangabad, for encouragement during the process of carrying out this work.

\section{REFERENCES}

[1] J. F. Swinbourne, H. J. Hunt and G. Klinkert, "An Efficient One Pot Synthesis of $4 H$-Pyrrolo[3,2,ij]quinolines," Advances in Heterocyclic Chemistry, Vol. 23, 1987, pp. 103-170. doi:10.1016/S0065-2725(08)60842-9

[2] J. V. Greenhill, "In Comprehensive Heterocyclic Chemistry," A. R. Katritzky and C. W. Rees, Eds., Pergamon Press, London, Vol. 5, 1984, p. 302.

[3] J. Elguero, "Evaluation of Antidepressant Effect of 2Pyrazoline Derivatives," In: A. R. Katritzky and C. W. Rees, Eds., Comprehensive Heterocyclic Chemistry, Pergamon Press, London, Vol. 3, 1996, p. 1.

[4] D. Nauduri and G. B. Reddy, "Synthesis and Activity of 2-Pyrazoline Derivatives," Chemical \& Pharmaceutical Bulletin, Tokyo, Vol. 46, 1998, pp. 1254-1260. doi:10.1248/cpb.46.1254

[5] S. S. Korgaokar, P. H. Patil, M. T. Shah and H. H. Parekh, Studies on Pyrazolines: Preparation and Antimicrobial Activity of 3-(3'(p-Chlorophenylsulphonamidophenyl)-5aryl-acetylpyrazolines," Indian Journal of Pharmaceutical Sciences, Vol. 58, No. 6, 1996, pp. 222-225.

[6] R. H. Udupi, A. R. Kushnoor and A. R Bhat, "Synthesis and Biological Evaluation of Certain Pyrazoline Derivative of 2-(6-Methoxynaphthyl)-propionic Acid," Indian Journal of Heterocyclic Chemistry, Vol. 8, No. 1, 1998, pp. 63-66.

[7] A. A. Bilgin, E. Palaska and R. Sunal, "Arzeimforsch; Evaluation of Antidepressant Effect of Pyrazoline Derivatives," Drug Research, Vol. 43, 1993, pp. 1041-1044.

[8] D. Azarifer and H. Ghasemnejad, "Microwave-Assisted Synthesis of Some 3,5-Arylated 2-Pyrazolines," Molecules, Vol. 8, No. 8, 2003, pp. 642-648. doi: $10.3390 / 80800642$

[9] D. Azarifer and M. Shaebanzadeh, "Synthesis and Characterization of New 3,5-Dinaphthyl Substituted 2-Pyrazolines and Study of Their Antimicrobial Activity," Molecules, Vol. 7, No. 12, 2002, pp. 885-895. doi: $10.3390 / 71200885$

[10] M. A. Ali, A. A. Siddiqui and M. S. Synthesis, "Structural Activity Relationship and Anti-Tubercular Activity of Novel Pyrazolines Derivatives," European Journal of Medicinal Chemistry, Vol. 42, No. 2, 2007, pp. 268-275. doi:10.1016/j.ejmech.2006.08.004

[11] M. Amir, H. Kumar and S. A. Khan, "Synthesis and Pharmacological Evaluation of Pyrazoline Derivatives as New Anti-Inflammatory and Analgesic Agents," Bioorganic \& Medicinal Chemistry Letters, Vol. 18, No. 3, 2008, pp. 918-922. doi:10.1016/j.bmcl.2007.12.043

[12] L. Knorr, "Notiz uber die Pyrazolinreaction," Berichte der Deutschen Chemischen Gesellschaft, Vol. 26, No. 1, 1893, pp. 100-103. doi:10.1002/cber.18930260123

[13] V. Malhotra, S. Pathak, R. Nath, D. Mukerjee and K. Shankar, "Substituted Imidazole Derivatives as Novel Cardiovascular Agents," Indian Journal of Chemistry, Vol. 41B, 2002, p. 1310.

[14] T. L. Ji, H. Z. Xiao and P. L. B. Zhi, “An Improved Synthesis of 1,3,5-Triaryl-2-pyrazolines in Acetic Acid Aqueous Solution under Ultrasound Irradiation," The Journal of Organic Chemistry, Vol. 3, No. 1, 2007, pp. 13-16.

[15] A. Levai, "Synthesis of Chlorinated 3,5-Diaryl-2-pyrazolines by the Reaction of Chlorochalcones with Hydrazines," Arkivoc, 2005, pp. 344-352.

[16] R. J. Grayer and J. B. Harborne, "A Survey of Antifungal Compounds from Higher Plants," Phytochemistry, Vol. 37, No. 1, 1994, pp. 19-42. doi:10.1016/0031-9422(94)85005-4

[17] O. N. Irob, M. Moo-Young and W. A. Anderson, "Antimicrobial Activity of Annatto Extract," International Journal of Pharmaceutics, Vol. 34, No. 2, 1996, pp. 8790. doi:10.1076/phbi.34.2.87.13201 